\title{
Sternum wound contraction and distension during negative pressure wound therapy when using a rigid disc to prevent heart and lung rupture
}

\author{
Sandra Lindstedt ${ }^{1 *}$, Richard Ingemansson ${ }^{1}$ and Malin Malmsjö ${ }^{2}$
}

\begin{abstract}
Background: There are increasing reports of deaths and serious complications associated with the use of negative pressure wound therapy (NPWT), of which right ventricular heart rupture is the most devastating. The use of a rigid barrier has been suggested to offer protection against this lethal complication by preventing the heart from being drawn up against the sharp edges of the sternum. The aim of the present study was to determine whether a rigid barrier can be safely inserted over the heart with regard to the sternum wound edge movement.

Methods: Sternotomy wounds were created in eight pigs. The wounds were treated with NPWT at $-40,-70,-120$ and $-170 \mathrm{mmHg}$ in the presence and absence of a rigid barrier between the heart and the edges of the sternum. Wound contraction upon NPWT application, and wound distension under mechanical traction to draw apart the edges of the sternotomy were evaluated.
\end{abstract}

Results: Wound contraction resulting from NPWT was similar with and without the rigid barrier. When mechanical traction was applied to a NPWT treated sternum wound, the sternal edges were pulled apart. Wound distension upon traction was similar in the presence and absence of a the rigid barrier during NPWT.

Conclusions: A rigid barrier can safely be inserted between the heart and the edges of the sternum to protect the heart and lungs from rupture during NPWT. The sternum wound edge is stabilized equally well with as without the rigid barrier during NPWT.

\section{Introduction}

The use of negative pressure wound therapy (NPWT) for the treatment of deep sternal wound infections has been shown to have remarkable effects on healing [1]. There are, however, increasing numbers of reports of deaths and serious complications associated with the use of NPWT due to heart rupture, lung rupture, bypass graft bleeding and death; the incidence being 4 to $7 \%$ of all patients treated for poststernotomy mediastinitis with NPWT after cardiac surgery [2-4]. In November 2009, the FDA filed an alert, and the importance of protecting exposed organs during NPWT and

\footnotetext{
* Correspondence: sandra.lindstedt@skane.se

'Department of Cardiothoracic Surgery, Lund University and Skåne University Hospital, Lund, Sweden

Full list of author information is available at the end of the article
}

this issue has also been emphasized in the international scientific literature [5-8].

We have previously elucidated the cause of heart rupture in pigs using magnetic resonance imaging $[9,10]$. The heart was shown to be drawn up towards the thoracic wall, the right ventricle bulged into the space between the sternal edges, and the sharp edges of the sternum protruded into the anterior surface of the heart, in some cases resulting in damage to the left ventricle of the heart or damage to a bypass graft to the right coronary artery [10]. Multiple layers of paraffin gauze over the anterior portion of the heart did not prevent the heart from being deformed. These events could, however, be prevented by inserting a rigid plastic disc between the anterior part of the heart and the inside of the thoracic wall [10]. Heart and lung ruptures

\section{Biomed Central}


similar to those seen in patients were observed in this experimental set-up without the rigid discs, while no damage to the heart or lungs was seen when the discs were used [10].

Several important aspects must be taken into consideration when treating a sternotomy wound with NPWT. The edges of the sternum move when the patient breaths, coughs and moves. Therefore, the sternum wound must be contracted and stabilized in order to allow adequate respiration and mobilization $[5,11]$. The aim of the present study was to investigate sternum wound contraction and distension in the presence and absence of a rigid barrier, inserted between the heart and the edges of the sternum, to protect the heart and lungs from damage and rupture during NPWT. Wound contractions were measured before and after negative pressures ranging from -40 to $-170 \mathrm{mmHg}$ were applied. Sternum wound distension during mechanical traction to pull apart the edges of the sternotomy, was evaluated using forces up to $320 \mathrm{~N}$.

\section{Material and methods}

\section{Animals}

A porcine sternotomy wound model was used. Eight domestic landrace pigs with a mean weight of $70 \mathrm{~kg}$ were fasted overnight with free access to water. The study was approved by the Ethics Committee for Animal Research, Lund University, Sweden. The investigation complied with the "Guide for the Care and Use of Laboratory Animals" as recommended by the U.S. National Institutes of Health, and published by the National Academies Press (1996).

\section{Anaesthesia and surgery}

Premedication was performed with an intramuscular injection of xylazine (Rompun ${ }^{\circledR}$ vet. $20 \mathrm{mg} / \mathrm{ml}$; Bayer AG, Leverkusen, Germany; $2 \mathrm{mg} / \mathrm{kg}$ ) mixed with ketamine $\left(\right.$ Ketaminol $^{\circledR}$ vet. $100 \mathrm{mg} / \mathrm{ml}$; Farmaceutici Gellini S.p.A., Aprilia, Italy; $20 \mathrm{mg} / \mathrm{kg}$ ). Before surgery, a tracheotomy was performed and an endo-tracheal tube was inserted. Anaesthesia was maintained with a continuous infusion of ketamine (Ketaminol ${ }^{\circledR}$ vet. $50 \mathrm{mg} / \mathrm{ml}$; 0.4-0.6 mg/kg/h). Complete neuromuscular blockade was achieved with a continuous infusion of pancuronium bromide (Pavulon; N.V. Organon, Oss, the Netherlands; 0.3-0.5 mg/kg/h). Fluid loss was compensated for by continuous infusion of Ringer's acetate at a rate of $300 \mathrm{ml} / \mathrm{kg} / \mathrm{h}$. Mechanical ventilation was established with a Siemens-Elema ventilator (Servo Ventilator 300, Siemens, Solna, Sweden) in the volume-controlled mode (65\% nitrous oxide, $35 \%$ oxygen). Ventilatory settings were identical for all animals (respiratory rate: 15 breaths/min; minute ventilation: $8 \mathrm{l} / \mathrm{min}$ ). A positive end-expiratory pressure of $5 \mathrm{cmH}_{2} \mathrm{O}$ was applied. A Foley catheter was inserted into the urinary bladder through a suprapubic cystostomy. Upon completion of the experiments, the animals were given a lethal dose $(60 \mathrm{mmol})$ of intravenous potassium chloride.

\section{Wound preparation}

A midline sternotomy was performed and the pericardium and the pleurae were opened. Two 6-0 steel wires for use in sternal closure (Syneture, Tyco Healthcare, CT, USA) were secured around the ribs on each side of the sternum, and attached to a custom-made sternal traction device. The purpose of this was to test sternum wound distension when lateral traction was applied to draw apart the edges of the sternotomy (Figure 1). The traction device was connected to a force transducer and a recorder. The wound was treated with NPWT in the presence or absence of a rigid plastic disc, which was inserted between the heart and the sternum. The wound was filled with open-pore polyurethane foam. One layer of foam was placed between the sternal edges. A second layer of foam was placed over the first layer, between the soft tissue wound edges, and secured to the surrounding skin. The wound was sealed with a transparent adhesive drape, and the drain was connected to the vacuum source. The vacuum source was set to deliver negative pressures of $-40,-70,-120$ or $-170 \mathrm{mmHg}$. The different negative pressures were applied in random order.

\section{Wound contraction}

The distance between the lateral wound edges was measured. Measurements were performed before and after

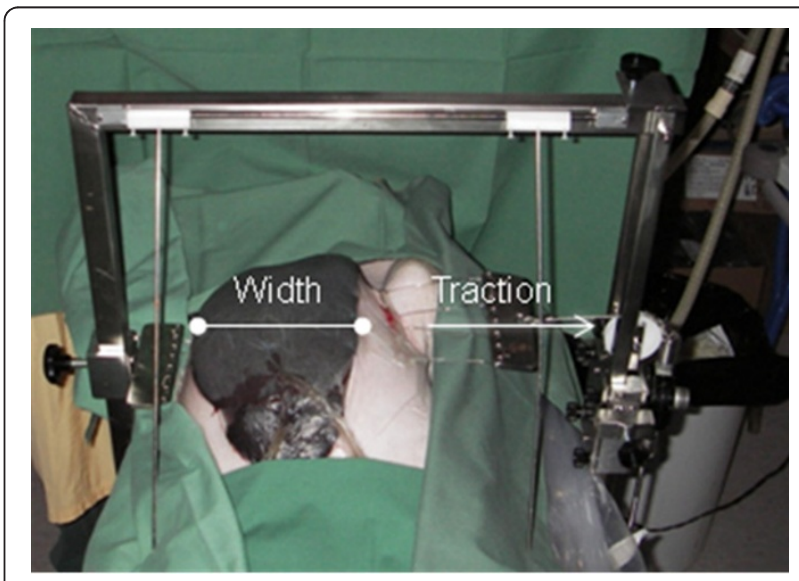

Figure 1 Photograph of the experimental set-up used to measure wound distension upon the application of a lateral force during NPWT. Negative pressure was applied with or without a rigid disc placed between the heart and the edges of the sternum. Two 6-0 steel wires were secured around the ribs on each side of the sternum and attached to a custom-made traction device. The traction device was connected to a force transducer and a recorder. Negative pressures of $0,-40,-70,-120$ and -170 $\mathrm{mmHg}$ were applied. The wound width was measured when traction forces between 0 and $320 \mathrm{~N}$ were applied to the lateral edges of the sternotomy 
the application of negative pressures of $-40,-70,-120$ and $-170 \mathrm{mmHg}$.

\section{Wound distension}

Lateral traction was applied to the sternotomy wound, using the traction device described above, and the distension of the wound was measured. The effects of lateral forces, ranging from 0 to $320 \mathrm{~N}$, were studied on the NPWT treated sternotomy wound, at the negative pressures of $-40,-70,-120$ and $-170 \mathrm{mmHg}$. This was done to ensure that the sternum is sufficiently stabilized during NPWT to withstand the forces to which the wound is exposed when the patient breathes, coughs or moves.

\section{The protective disc}

The protective disc was made out of bio-compatible plastic that could withstand a force of a negative pressure of at least $-50 \mathrm{mmHg}$. The disc was $20 \times 8 \mathrm{~cm}$ and was then cut to appropriate size to fit between the anterior part of the heart and the posterior part of the sternum. The disc had multiple small perforations all over the disc area to allow drainage. The disc was ridged with flexible edges.

\section{Calculations and statistics}

Calculations were performed using GraphPad 5.0 software (San Diego, CA, USA). Statistical analysis was performed using the Mann-Whitney test when comparing two groups and the Kruskal-Wallis test with Dunn's post-test for multiple comparisons when comparing three groups or more. Significance was defined as $\mathrm{p}<$ 0.05 . Results are presented as the mean of 8 measurements \pm the standard error of the mean (S.E.M.).

\section{Results}

\section{Wound contraction under NPWT}

Various negative pressures $(-40,-70,-120$ and $-160 \mathrm{mmHg}$ ) were applied to the sternal wound and the width of the wound was measured. Wound contraction was similar in the presence and absence of a rigid disc between the heart and the sternum during NPWT. Detailed results are shown in Figure 2.

\section{Wound distension under NPWT and traction}

After the application of each negative pressure, increasing levels of lateral traction were applied. This caused the sternum wound edges to be pulled apart. The increase in the width of the wound was determined at each force. The sternum wound distension upon traction was similar with and without the rigid disc during NPWT, indicating similar sternum stability. Different levels of negative pressure $(-40,-70,-120$ and $-170 \mathrm{mmHg}$ ) allowed similar lateral distortion of the sternum wound edges. Detailed results are shown in Figure 3.

\section{Discussion}

NPWT improves the healing of poststernotomy mediastinitis. One of the major advantages of applying NPWT to sternotomy wounds is that it stabilizes the sternum, which facilitates respiration and allows early mobilization

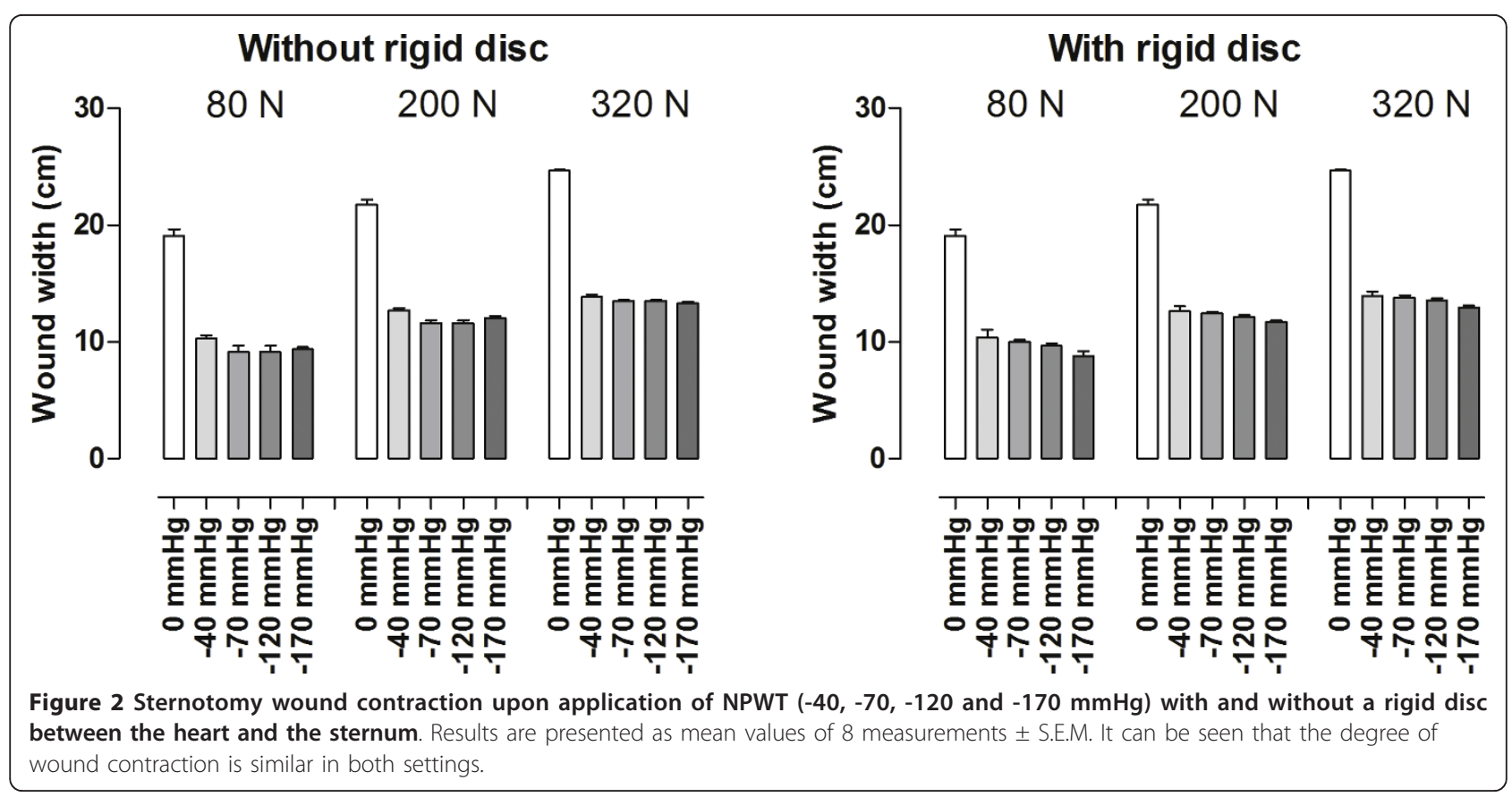




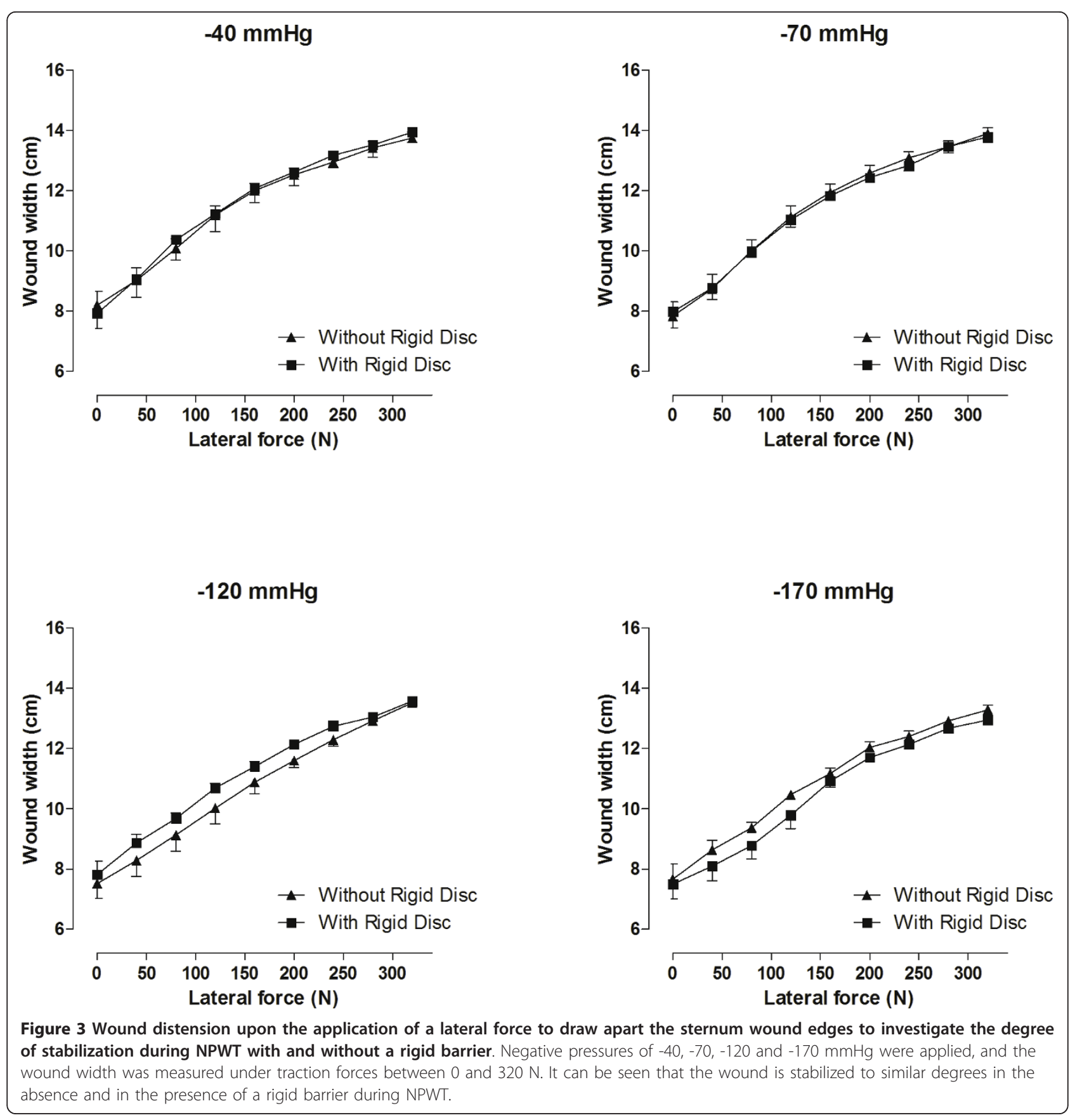

$[5,6]$. However, complications associated with bleeding and heart rupture with lethal outcome have been reported in several studies $[2,4,12]$. The insertion of a rigid barrier between the heart and the sharp edges of the sternum has been suggested to prevent such complications [10]. In the present study, sternum wound contraction and stabilization in the presence and absence of a rigid barrier during NPWT were examined. These are important to ensure the safety and efficacy of the negative pressure treatment of a sternotomy wound.

\section{Wound contraction}

Contraction is important in a sternotomy wound to both accelerate healing and stabilize the wound. Wound contraction was observed in when NPWT was applied, and was similar in the absence and presence of a rigid barrier disc. Wound contraction is known to result in mechanical deformation of the wound edge tissue [13-15], which results in shearing forces at the wounddressing interface that will affect the cytoskeleton [16] and initiate a cascade of biological effects ultimately 
resulting in granulation tissue formation and wound healing [14]. Indeed, it has been shown that early changes in the size of a wound are correlated to the rate of wound healing [17].

\section{Sternum wound stabilization}

A sternotomy wound requires certain safety measures with regard to exposed vital organs. The sternum wound edges move when the patient moves, coughs and breaths, and the sternum wound must be contracted and stabilized for the treatment to be considered safe. Sternum wound stabilization is also important to ensure adequate respiration and mobilization during NPWT $[5,11]$. In this study, sternum wound stabilization can be tested by applying a lateral traction force to pull the sternal edges apart and force the wound to open. The results show that even at low levels of negative pressure $(-40$ and $-80 \mathrm{mmHg})$, the sternum is significantly stabilized. It has previously been reported that wound stabilization is similar at low levels of negative pressure $(-50$ to $-100 \mathrm{mmHg}$ ) and high levels of negative pressure $(-150$ to $-200 \mathrm{mmHg})$ [11]. The present study also shows that wound distension upon traction is similar in the absence and presence of a disc to protect the heart and lungs during NPWT. These results suggest that a rigid barrier can be safely placed in the sternotomy wound to protect the heart and lungs from damage and rupture during NPWT, with regard to sternum wound contraction and distension.

\section{Conclusions}

The most feared complication of NPWT-treated poststernotomy mediastinitis is heart rupture. The cause of right ventricular rupture may be contact with the sharp sternal edges as the heart is drawn up towards the thoracic wall. The use of a rigid barrier between the heart and the edges of the sternum has been shown to prevent this movement, and has been proposed as a means of preventing heart rupture. In the present study we show that the sternum wound is contracted and stabilized equally well in the presence as in the absence of a rigid barrier disc, inserted between the heart and the sternal edges during NPWT. This study provides evidence that a rigid disc can safely be inserted over the heart, for protection during NPWT with regard to sternum wound contraction and stabilization.

\section{Acknowledgements}

This study was supported by the Swedish Medical Research Council, Lund University Faculty of Medicine, the Swedish Government Grant for Clinical Research, Lund University Hospital Research Grants, the Swedish Medical Association, the Royal Physiographic Society in Lund, the Åke Wiberg Foundation, the Anders Otto Swärd Foundation/Ulrika Eklund Foundation, the Magn Bergvall Foundation, the Crafoord Foundation, the Anna-Lisa and
Sven-Erik Nilsson Foundation, the Jeansson Foundation, the Swedish HeartLung Foundation, Anna and Edvin Berger's Foundation, the Märta Lundqvist Foundation, and Lars Hierta's Memorial Foundation.

\section{Author details}

'Department of Cardiothoracic Surgery, Lund University and Skåne University Hospital, Lund, Sweden. ${ }^{2}$ Department of Ophthalmology, Lund University and Skåne University Hospital, Lund, Sweden.

\section{Authors' contributions}

SL, RI \& MM carried out the experimental studies. SL drafted the manuscript. MT participated in the sequence alignment. SL, RI \& MM participated in the design of the study and performed the statistical analysis. All authors read and approved the final manuscript.

\section{Competing interests}

The authors declare that they have no competing interests.

Received: 3 November 2010 Accepted: 30 March 2011

Published: 30 March 2011

\section{References}

1. Sjogren J, Gustafsson R, Nilsson J, et al: Clinical outcome after poststernotomy mediastinitis: vacuum-assisted closure versus conventional treatment. Ann Thorac Surg 2005, 79(6):2049-55.

2. Sartipy U, Lockowandt U, Gabel J, et al: Cardiac rupture during vacuumassisted closure therapy. Ann Thorac Surg 2006, 82(3):1110-1.

3. Ennker IC, Malkoc A, Pietrowski D, et al: The concept of negative pressure wound therapy (NPWT) after poststernotomy mediastinitis-a single center experience with 54 patients. J Cardiothorac Surg 2009, 4:5.

4. Khoynezhad A, Abbas G, Palazzo RS, et al: Spontaneous right ventricular disruption following treatment of sternal infection. J Card Surg 2004, 19(1):74-8.

5. Gustafsson Rl, Sjogren J, Ingemansson R: Deep sternal wound infection: a sternal-sparing technique with vacuum-assisted closure therapy. Ann Thorac Surg 2003, 76(6):2048-53, discussion 2053.

6. Hersh RE, Jack JM, Dahman MI, et al: The vacuum-assisted closure device as a bridge to sternal wound closure. Ann Plast Surg 2001, 46(3):250-4.

7. Malmsjo M, Ingemansson R, Sjogren J: Mechanisms governing the effects of vacuum-assisted closure in cardiac surgery. Plast Reconstr Surg 2007, 120(5):1266-75.

8. Sjogren J, Malmsjo M, Gustafsson R, et al: Poststernotomy mediastinitis: a review of conventional surgical treatments, vacuum-assisted closure therapy and presentation of the Lund University Hospital mediastinitis algorithm. Eur J Cardiothorac Surg 2006, 30(6):898-905.

9. Petzina R, Ugander M, Gustafsson $L$, et al: Hemodynamic effects of vacuum-assisted closure therapy in cardiac surgery: assessment using magnetic resonance imaging. J Thorac Cardiovasc Surg 2007 133(5):1154-62.

10. Malmsjo M, Petzina R, Ugander $M$, et al: Preventing heart injury during negative pressure wound therapy in cardiac surgery: assessment using realtime magnetic resonance imaging. J Thorac Cardiovasc Surg 2009, 138(3):712-7.

11. Mokhtari A, Petzina R, Gustafsson L, et al: Sternal stability at different negative pressures during vacuum-assisted closure therapy. Ann Thorac Surg 2006, 82(3):1063-7.

12. Abu-Omar Y, Naik MJ, Catarino PA, et al: Right ventricular rupture during use of high-pressure suction drainage in the management of poststernotomy mediastinitis. Ann Thorac Surg 2003, 76(3):974-5, author reply 974 .

13. Argenta LC, Morykwas MJ: Vacuum-assisted closure: a new method for wound control and treatment: clinical experience. Ann Plast Surg 1997, 38(6):563-76, discussion 577

14. Morykwas MJ, Argenta LC, Shelton-Brown El, et al: Vacuum-assisted closure: a new method for wound control and treatment: animal studies and basic foundation. Ann Plast Surg 1997, 38(6):553-62.

15. Morykwas MJ, Simpson J, Punger K, et al: Vacuum-assisted closure: state of basic research and physiologic foundation. Plast Reconstr Surg 2006, 117(7 Suppl):121S-126S.

16. Saxena V, Hwang CW, Huang S, et al: Vacuum-assisted closure: microdeformations of wounds and cell proliferation. Plast Reconstr Surg 2004, 114(5):1086-96, discussion 1097-8. 
17. Lavery LA, Barnes SA, Keith MS, et al: Prediction of healing for postoperative diabetic foot wounds based on early wound area progression. Diabetes Care 2008, 31(1):26-9.

doi:10.1186/1749-8090-6-42

Cite this article as: Lindstedt et al:: Sternum wound contraction and distension during negative pressure wound therapy when using a rigid disc to prevent heart and lung rupture. Journal of Cardiothoracic Surgery 2011 6:42.

Submit your next manuscript to BioMed Central and take full advantage of:

- Convenient online submission

- Thorough peer review

- No space constraints or color figure charges

- Immediate publication on acceptance

- Inclusion in PubMed, CAS, Scopus and Google Scholar

- Research which is freely available for redistribution

Submit your manuscript at www.biomedcentral.com/submit 